of expeditions which were sent from the United States with the object of securing data on various astronomical matters. In 1847 Lieut. J. M. Gilliss, founder of the U.S. Naval Observatory, induced Congress to authorize and finance an expedition to South America to improve the value of the solar parallax. Cerro Santa Lucia in Chile was chosen as the site for the observatory, and great progress was made in the next three years, during which the positions of Mars and Venus were determined simultaneously in Chile and in the United States, mostly at Cambridge. Several years later, the reduction of these observations was carried out and a solar parallax of $8 \cdot 5^{\prime \prime}$ was derived. Research was conducted in other directions, and eventually the Chilean Government became so interested in the work that it arranged for young Chileans to be taught the use of the instruments. Later it purchased these and founded a National Observatory. Dr. Benjamin Gould, who had carried out the reductions for the solar parallax, interested Sarmiento, the Argentine ambassador to the United States, in a scheme for determining accurate star positions in a zone where observations were lacking, and the result was that the Argentine Government founded El Observatorio Nacional de Argentina in 1870, Gould being chosen as director.

Among other projects in South America, reference is made to another Argentine observatory, built at San Luis, through the influence of Prof. Lewis Boss, director of the Dudley Observatory in Albany, New York. This Observatory obtained a total of 85,000 star positions between 1909 and 1911. Before this, so early as 1890 , Prof. S. I. Bailey established a station for the Harvard College Observatory in Arequipa, Peru ; this was transferred to South Africa in 1926. In 1903 Prof. W. H. Wright established a station on Cerro San Christobal on the outskirts of Santiago for determining radial velocities. This station was known as the D. O. Mills Expedition of the Lick Observatory, and when the work was completed, the equipment was sold for a nominal price to the Catholic University of Chile. These and other astronomical ventures have established creditable cultural relations and lasting good-will between races with differences in customs, aspirations, and mode of thought, and have led to a better understanding of both scientific and political problems.

\section{Origin of Meteorites}

H. H. Mrninger, Colorado Museum of Natural History, in a paper entitled "Trends in Meteoritics" (Sky and Telescope, 1, 8; June, 1942), gives a short résumé of our knowledge of meteorites. Most hypotheses in the past regarding the origin of these bodies gave more attention to iron than to stone meteorites, and erroneous conclusions were drawn. Chondrules, the most abundant of all meteoric constituents, have almost certainly been formed by repeated collisions between crystals and other solid bodies. For this reason, a situation which would provide for the rounding of crystals into chondrules would also produce the fragmentary matrix in which chondrules are usually embedded. It is suggested that in the past, when the sun was more active, extruded gases crystallized and collected into cometary swarms and within these swarms chondrules were produced by repeated collisions, while the aggregation of the resulting fragments and chondrules gave rise to meteorites. Some of the cometary swarms passed close enough to the sun to allow for the fusing of a percentage of the constituent grains, and this process was carried almost to the point of completely fusing the mass in the Lubbock aerolite, which was described in the American Mineralogist $(25,528-33 ; 1940)$.

It is surprising to learn that a considerable proportion of stony material which enters our atmosphere is reduced to dust. Dr. Lincoln La Paz has estimated that the Pasamonte meteorite weighed 66,000 tons at least when it entered the atmosphere, but only $4,000 \mathrm{gm}$. were collected. A huge dust cloud occupying about 1,000 cubic miles accounted for the principal mass of this meteorite. Further research on meteors may well yield useful information on the past history of the solar system.

\section{The Beet Leafhopper}

THrs insect, known scientifically as Eutettix tenella, forms the subject of Farmer's Bulletin No. 1886 (1941) of the U.S. Department of Agriculture, by W. C. Cook. We note in this publication a markedly enlarged dimension of its pages as compared with the usual run of its predecessors. Its value is thus enhanced by allowing of larger scale and more detailed illustrations and of a more convenient spacing of the letterpress. The beet leafhopper is native to the western United States and to northern Mexico, and is notorious as the carrier and transmitter of the virus of the destructive curly top disease of sugar beet and also of western yellow blight of tomatoes. During many years past the curly top disease has been a major factor limiting the production of sugar beet in many western areas. The whole problem of its control is $\mathbf{a}$ difficult one since direct spraying is rarely of value. In many areas the control of grazing is the most feasible method of attacking many of the plant hosts of this insect. In some cases reduction or elimination of the Russian-thistle, the most important summer host, by mechanical means is possible. The actual status of the natural enemies of the leafhopper is difficult to assess, but they are considered to be of great importance. The most notable are flies of the family Pipunculidæ and parasitic wasps of the Dryinidæ group. Predacious bugs, one of which is Geocoris pallens, are said to be of equal importance as parasites in reducing its numbers. The development and successful production of strains of beet resistant to the curly top disease has greatly reduced the losses incurred by the spread of the virus disease. By this means the cultivation of sugar beet has been made possible in districts formerly found to be unsuitable.

\section{Earthquakes Registered in Switzerland}

ACCORDING to bulletins just received concerning earthquakes registered at the observatories of Zurich, Basle, Neuchâtel and Chur, fifteen earthquakes were consistently registered during February 1942 and nine strong earthquakes during March. Many of these have been mentioned previously in the columns of NATURE, but epicentres on the European continent can now be given. On February 6 an earthquake recorded at Zurich at $00 \mathrm{~h} .10 \mathrm{~m}$. $46.6 \mathrm{~s}$. had its epicentre in the Rheintalgraben to the south of Freiburg. On February 7 an earthquake recorded at Zurich at $03 \mathrm{~h} .55 \mathrm{~m}$. $41 \cdot 4 \mathrm{~s}$. had its epicentre near Venice. This was strongly recorded at all the stations. On February 12 an earthquake registered at Zurich at $16 \mathrm{~h} .03 \mathrm{~m} .17 \cdot 5 \mathrm{~s}$. had its 
epicentre east of the Pelvoux-Massiv, in the Westalpen. This shock also was strongly recorded at all observatories. On February 17 an earthquake with its epicentre between Simmental and Kandertal in the Berneroberland was strongly recorded at all stations, the recording at Zurich being at $11 \mathrm{~h} .14 \mathrm{~m}$. $58 \cdot 8 \mathrm{~s}$. On February 22 an earthquake recorded at Zurich at $22 \mathrm{~h} .34 \mathrm{~m} .38 \cdot 8 \mathrm{~s}$. had its epicentre near the Stuttgart Rheintalgraben. The earthquake of February 28 (Zurich, 13h. $49 \mathrm{~m}$. 13.4s.) had its epicentre in the Bodenunruhe, and that of March 15 (Neuchâtel, 16h. $06 \mathrm{~m} .27 \cdot 8 \mathrm{~s}$.) its epicentre to the south-east of the Neuenburgersee.

During April and May, 1942, thirty-one strong earthquakes were registered by the seismographs at the Swiss Observatories of Zurich, Basel, Neuchâtel and Chur, according to bulletins just received from Zurich. One epicentre, not mentioned previously in the columns of NATURE, is for the earthquake of April 12. The shock was recorded at Zurich at 00 h. $02 \mathrm{~m}$. 53.9 U.T. and apparently came from an epicentre $420 \mathrm{~km}$. distant. This epicentre is most likely to have been in the Udine Province of Italy.

\section{Trachoma in the Argentine}

According to the April issue of the Boletin de la Medicina Sanitaria Panamericana, the provinces of Tucumán, Santiago del Estero, Santa Fé, Entre Rios, Corrientes, Salta, Jujuy and Misiones form the area most seriously affected by trachoma in the Argentine. The school is the centre for the control of the disease in children; specially trained doctors examine the children before school begins, and those found infective are given treatment in dispensaries and are not admitted to school until their eyes are normal. Meanwhile, the patients are visited by public health nurses, who instruct the family in treatment and prevention. Periodic visits to schools and dispensaries are made by medical inspectors of the National $\mathrm{De}$ partment of Health, and teachers serve as intermediaries between the medical practitioner and the children. Intensive educational work is carried out by posters, leaflets and lectures, and preventive medicines are distributed. The result of this campaign during the last few years has been a reduction of the percentage of children infected with trachoma.

\section{Yellow Fever in the Americas}

Is a recent paper (Bol. Of. San. Panamericana, 21, 320 ; 1942), Dr. Wilbur A. Sawyer, director of the Division of International Health, Rockefeller Foundation, New York, discusses the following features of the yellow fever situation in South America: (1) the absence of a definite outbreak of urban yellow fever transmitted by $A$. ogypti; (2) the absence of yellow fever of any type recognized outside South America; (3) the presence of jungle yellow fever, which takes the form of endemics, or epidemics spread over wide areas of South America. The chief features of control methods consist in weekly inspection of premises for A. cegypti larvæ, destruction of breeding-places and search for other mosquitoes by special squads. While cities may be kept free from infection by $A$. cegypti control, vaccination is the only measure practicable against jungle yellow fever; it can be carried out on a large scale and has been found both safe and effective.

\section{Oil-bearing Plants in Sweden}

According to the June issue of the Anglo-Swedish Review, the cultivation of oil-bearing plants in Sweden has developed rapidly. In 1940 the area covered by such plants was only 938 acres, whereas in 1941 it was 21,250 acres, yielding a harvest of 10,000 tons of seed from which 2,700 tons of oil could be produced and 7,000 tons of fodder. This year it is established that the oil plant area is 42,500 or 45,000 acres, out of which 5,000 acres is rape, 32,500 acres white mustard, 1,000 acres poppy seed and 2,500 linseed. The yield will be at least 20,000 tons of seed, from which 6,000 tons of oil can be extracted, representing a little more than one tenth of the normal consumption of margarine in Sweden. It is considered likely that the cultivation of oil plants will be so extended that it will be possible to cover one fourth of the normal requirements of raw material for the manufacture of margarine.

\section{University of London}

THe following appointments have been made in the University of London: Dr. F. G. Young, since 1936 a member of the scientific staff of the Medical Research Council, to the University chair of biochemistry tenable at St. Thomas's Hospital Medical School; Mr. B. W. Windeyer, medical officer in charge of the Meyerstein Institute of Radiotherapy, Middlesex Hospital, to the University chair of radiology tenable at Middlesex Hospital Medical School; Dr. Alexander Lawson, lecturer in chemistry at University College, Southampton, to the University readership in organic chemistry tenable at the London (R.F.H.) School of Medicine for Women.

The title of reader in education in the University has been conferred on Mr. J. A. Lauwerys in respect of the post held by him at the Institute of Education.

\section{Announcements}

Sir Gur Marshatr has resigned from the directorship of the Imperial Institute of Entomology. He is succeeded by Dr. S. A. Neave, who has been assistant director since 1913.

SIR LouIs STERLING has been elected president of the British Institution of Radio Engineers in suecession to Dr. C. C. Garrard. The presidential address, which is expected to deal with registration of engineers, will be read before the London Section of the Institution at a meeting to be held at the Federation of British Industries, 21 Tothill Street, Westminster, S.W.1, on September 25.

Applicatrons for the conditions of the competition for the Jones-Bateman Cup, offered triennially for original research in fruit culture which has added to our knowledge of cultivation, genetics, or other relative matters, may be had on application to the Secretary, Royal Horticultural Society, Vincent Square, Westminster, London, S.W.1.

Errata. "Relationships of some Primitive Tetrapods", by Dr. T. S. Westoll (NATURE, July 25, p. 121): paragraph 2 , line 4, for "Burdie-house" read "Burdiehouse"; paragraph 4, line 3, should read ". . . strata of latest Dinantian (Viséan) and Namurian age. . . ." 